\title{
Together apart: Hackney Wick, the Olympic site and relational art
}

Isaac Marrero-Guillamón

4 November 2014

The complex relationship between Hackney Wick and the Olympic site is explored through two relational art projects by Jim Woodall and public works.

Isaac Marrero-Guillamón is lecturer in Anthropology at Goldsmiths, University of

London. His research focuses on the post-Fordist city, the articulation of new forms of collective action, and the politics of representation. 
As soon as the bid to host the 2012 Olympics was won by London in 2005, and the plans to build the Olympic site in the Lower Lea Valley were announced, an inconspicuous yet steady stream of artistic projects started to interrogate the impact that the transformation of the area would have on its inhabitants, landscape and social life. This undercurrent of criticality, largely invisible to the mainstream, offered an alternative to the official account of the process - one that spoke of displacement, surveillance and the effacement of local history. Through a myriad of artworks, images, events and discussions, an important space of dissent was produced in the lead up to the Games.1 The relational, collective and public dimension of these artistic practices is explored in the first part of this article, via an analysis of Jim Woodall's Olympic State project in Hackney Wick.

The second part of the article turns to the post-Olympic period in the same area, a context characterised by a new set of concerns related to the articulation of a new relationship between the Olympic site and its surroundings, the delivery of "legacy" and increased pressure from private developers. Through a discussion of the project $\mathrm{R}-$ Urban Wick by art/architecture collective public works, I explore the role of relational art in the vindication of local makeshift cultures in the future of the area and the enactment of spaces of dialogue between local residents, practitioners and public authorities.

Taken together, these two projects provide a fruitful platform for analysing the complex relationship between the Olympic site and one of its neighbouring areas, as mediated through art practice.

\section{Part 1}

On a cold Saturday morning in January 2011, on a rooftop in Hackney Wick, standing in front of a makeshift hut, artist Jim Woodall talked about his work Olympic State to an audience of approximately twenty people. The previous November he had installed a full CCTV surveillance system on this warehouse rooftop overlooking the Olympic site, complete with security cameras, monitors, and recording devices. He had lived in the 
$3 \times 3 \mathrm{~m}$ hut for two weeks, in a permanent state of vigilance vis-à-vis the tedious construction routines unfolding across the canal and on the screens. The equipment had since been removed, so upon entering the hut one had to imagine the split-screen camera feeds, the purr of the computers, the stale air. The bunk bed and the empty bottles of whisky remained, and allowed one to add some detail to the imaginary reconstruction of life in the hut. Woodall explained that the inspiration for the design came from hunting huts in Malta, and showed us pictures that made it evident. He had used mostly found or repurposed materials for the construction: timber beams for the structure, scrap wood panels for the interior coating, a narrow plexiglass sheet in lieu of a window, and foam-filled cardboard boxes wrapped in plastic for the exterior skin. The hut had withstood a tough winter, including various snowfalls, without major deterioration. It had been pretty warm inside too, he said, thanks to the heat that emanated from the screens. Some of us were surprised he had been able to live there and surveil the heavily policed Olympic site for two weeks without encountering problems. Woodall explained that the police had indeed paid him a visit, but left him alone once they were assured the hut was an artistic project. The art label remarkably provided a plausible alibi for what could have otherwise been identified as a subversive activity.

The discussion around whether art could be an appropriate terrain from which to launch a critical examination of the Games was in fact the reason why the visit to the rooftop had been organised in the first place. Woodall's presentation was part of a walking tour of the perimeter of the Olympic site led by Peter Coles, itself part of a two-day conference in which academics, activists and artists from London and Barcelona discussed the relationship between the mega-event, urban regeneration, critical artistic practice and grassroots politics. 2

Woodall's work was a clever radicalisation of the climate of mistrust and paranoia that defined the relationship between the Olympic site and Hackney Wick. What had once been a single post-industrial area spanning across both sides of the Hackney Cut canal had become two separate worlds, kept apart by a military-grade, CCTV-loaded 3,000-volt electric fence. The Wick (as locals call it) was a peculiar island - isolated from the rest of the city by canals and motorways, rather quiet and familial, home to a wide variety of light industries and around 700 artist studios. 3 Woodall was one of 
several local artists engaging critically with the transformation that the Olympics was bringing about. His work shows some of the ways in which artistic projects enabled the production of spaces of encounter and dissent.

In April 2011, Olympic State was re-installed in a new gallery (See Studio) a mere three minute walk from the warehouse where it had originally stood (Woodall had previously dismantled the structure, numbered the parts, and stored them to allow future reconstruction). The exhibition consisted of the reassembled hut (complete with its whisky bottles, microwave, sleeping bag), the two weeks of original footage playing on the monitors inside, and a series of video stills framed and hung on the walls. The gallery context had obviously transformed Olympic State - as the press release declared, it was now a monument to the original performance - but with the Olympic site only 250 metres away and construction work still under way, the counter-surveillance images still carried a great deal of force. Olympic State was also remarkable in its material presence: the hut hadn't been subject to conservation treatments and its smell carried with it a trace of its history; it was also there for people to use, rather than contemplate, and, on occasion, groups gathered inside [Fig. 1]. The political dimension of the work, however, had arguably been tamed by the new context - the reconstruction of the hut was, after all, a much less radical gesture than an actual counter-surveillance unit installed without permission on a rooftop and inhabited for two weeks.

Woodall was well aware of this from the outset. He was concerned about the loss of the project's performative dimension and sought to resist it. He invited Cristina Garrido and me to co-curate with him a performance event as part of the exhibition, a 24-hour marathon of screenings, presentations, discussions and live music to "activate" the project in a more performative fashion and reenact some of the endurance test-like quality of its original incarnation. The resulting event, 24-b Olympic State, took place on 5-6 May 2011 [Fig.2] and involved presentations, screenings and performances by 16 participants including artists, curators, photographers, musicians, architects and researchers. A limited-run zine publication, including an introductory text and contributions by the participants, was also produced and distributed on the day.

24-h Olympic State allows us to consider the specificity of artistic practices of assembling, a central aspect of the question of the role that art may play in the 
production of spaces of dissent. In what follows, I'll discuss how during those 24 hours, Woodall's solitary gesture of defiance was transformed into a platform for collective enunciation.

Two main concerns structured the event: the activation of local history "from below", and the critical engagement with the politics and aesthetics of surveillance. These two themes provided a transversal common ground for practitioners and researchers coming from different perspectives and traditions - as well as being key contributions towards a critical understanding of the impact of the Olympics on East London in their own right.

The screening of Hilary Powell's The Games (2007), for instance, brought into view the geography of disappearance associated with the Olympics: the film travelled through spaces that no longer existed and offered a glimpse of the unregulated and un-policed landscape frequently recalled by participants that evening. The Cut, commissioned by Space Studios, combined social science and artistic approaches (oral histories, archival research, participatory methods, drawing, photography) to glean a social history of the area's canals. Chris Dorley-Brown's pictures, for example, mapped the transformation of the landscape re-visiting the locations of archival photographs and producing beforeand-after dyptychs. Martin Slavin, from Games Monitor, presented an epic photographic survey of the impact of the Olympics on the Lower Lea Valley, including a systematic record of its effects on plants, animals, the environment and displaced residents. In all these projects, memory was an instrument against the systematic effacement of history that the Olympic development relied on. Whereas the official documents and surveys had defined the area as contaminated wastelands in desperate need of cleansing and regeneration, these projects articulated an alternative narrative, one that spoke of the freedom of interstitial spaces, subterranean social practices, and unregulated plant and animal life.

The second theme, surveillance, constituted the main part of the event; it stemmed directly from Olympic State and in fact dictated to a large extent the structure and language of the event: an overall climate of light paranoia was cultivated through the installation of CCTV cameras in and outside the gallery (streamed live through a projector on a gallery wall) [Fig. 3], the time coding of the event, and the design of the poster and the zine. Of course, the projects presented contributed their part too. 
Giles Price's Amber Alert explored photographically the military fence protecting the Olympic site, probably the clearest physical manifestation of the state of exception the Games required to operate. Adnan Hazdi presented Depford.tv's experiments in counter-surveillance filmmaking, including techniques for 'acquiring' live CCTV footage. Solina Hi-Fi's live concert was inspired by the aesthetics of surveillance - both the music and the performance: they played in their studio (upstairs in the same factory building) and their image was broadcast to the audience in the gallery via CCTV cameras. Charli Hope's Black Baloon, a short "improvised" film based on the free drift across London of a video camera attached to a helium-filled balloon, was a poetic détournement of the ability to control attributed to the "view from above".

The selection of participants, the audience that congregated, and the atmosphere 4 generated throughout the event clearly influenced the discussions held, which dwelled insistently on the regime of surveillance the Olympics had manifestly brought to an area previously famous for its institutional abandonment. The evening debate, following the first cluster of presentations, was particularly lively and went on till the live music started. People shared memories of an unruly, not so distant past, punctuated by black markets, burnt cars, illegal raves, and very cheap rents. It had, I'd argue, a political edge: far from a sentimental retreat to the past, this was remembering as a form of (soft) revenge - it was about not allowing things to be forgotten.5

In a context where most cultural institutions, mainstream media, local councils and even universities generally avoided engaging critically with the Olympics (at least in public), events such as $24-b$ Olympic State played an important role in making public an antagonistic account of the mega-event and bringing people together to engage with it. In fact, this particular event tapped into, and contributed to, an established practice amongst local artists, who had, for years and in different formats, got together to show and discuss work that interrogated the Olympics. Space Studios' pioneered this with their Legacy Now annual events (2005-2012) and the Olympic Artists Forum (20052008), later revitalised by Hilary Powell as Salon de Refuse Olympique (2008-2011). Since 2010, public works' has hosted regular public discussions on related topics, called the Wick Sessions. These events provided a continuing forum for discussing the Olympic-led transformation of East London which went well beyond their arts 
upbringing - amongst the participants and the audience one would routinely find activists, academics and neighbours.

My interest isn't however in simply corroborating the fact that art was instrumental in producing these spaces of dissent, but in teasing out their specific qualities compared to other forms of assembly. 24-h Olympic State enacted a very particular kind of aesthetic experience. First, there was the event's extreme duration: the 24-hour cycle of non-stop activity created a tangible atmosphere of exhaustion, even if most of the audience didn't experience the full length. Secondly, the so-called neutrality of the gallery space was clearly disturbed. As the event progressed, the traces and debris of previous visitors increasingly crept into the immaculate white cube, transforming it into a humble repository of actions past. Last but not least, the boundary between the artistic performance and other forms of social activity was blurred at times, if not inexistent. No doubt aided by the inclusion of food and live music as integral parts of the programme, as well as the availability of alcoholic beverages, the event must have looked virtually indistinguishable to an elaborate party to an onlooker. And yet, people hadn't gathered (solely) to have a good time - they had been explicitly summoned to experience and discuss a bunch of politically-minded art, and so they did.

At one level, Woodall's work can be conceptualised as "relational art" or "relational aesthetics". This concept, coined by Nicholas Bourriaud, refers to artistic practices that "take as their theoretical and practical point of departure the whole of human relations and their social context, rather than an independent and private space".6 Contrary to object-based art, relational art is concerned with the production of social relations, intersubjective encounters, even "microtopias" or models of alternative sociability. The participation of the audience, therefore, becomes the very matter of relational art and its political dimension, as "viewers are not just addressed as a collective, social entity, but are actually given the wherewithal to create a community, however temporary or utopian this may be."7 Leaving aside its content momentarily, it could be argued that at a formal level 24-b Olympic State's political dimension had to do with creating the conditions for social encounter and debate. One could even say that the event was the encounter between a series of practitioners and an audience - the conversations that took place, the connections that were made, the drinks that were shared. 
There are, to be sure, elements of relational aesthetics in Woodall's work, but also important points of departure from it, particularly in relation to its political dimension. I think it would be inadequate to simply celebrate the social encounter in itself and disregard the actual content of the presentations and discussions that took place during the event. After all, 24-b Olympic State had little to do with the celebration of a community. Rather, it wanted to be a medium for actively challenging the hegemonic discourse about the Olympics through a proliferation of new voices and subjectivities. This didn't take the form of a consensual community, but, as Deleuze would have it, an alliance or affinity between those in disagreement with the dominant state of affairs. The work of Jacques Rancière is here particularly useful to advance this alternative understanding of being together.

Rancière argues that the political power of art lies in its capacity to produce dissensus, or in other words, a rupture in the prevailing "distribution of the sensible" i.e. what is sayable, visible, and thinkable in a given context, and the concomitant partition of the people between those who are subjects of speech and those who aren't. Politics happens when new objects and subjects disrupt a particular consensus or cartography of perception; when that which was not visible is made visible, when those who were ignored become audible as speaking beings. In this process, "new modes of political construction of common objects and new possibilities of collective enunciation" become possible. 8 The kind of "community" Rancière envisions as woven by artistic practice is rather different from that typical of relational art (as conceptualised by Bourriaud). Inspired by Mallarmé's line “Apart, we are together", he argues that "to the extent that it is a dissensual community, an aesthetic community is a community structured by disconnection”. 9 The artwork becomes both (paradoxically) a people yet to come and a "monument to its expectation".

I believe that this understanding of a community of dissent as a continuously receding horizon (yet monumentalised in the present) beautifully captures the collective and political dimension of Woodall's project. On the one hand, 24-h Olympic State assembled people to challenge and antagonise with the 2012 Games. It was an occasion to talk and hear about increased surveillance and policing, the effacement local history, the displacement of local people, the disruption of the area's eco-system, etc. At the 
same time, through artistic methods, a collective, critical, and far from unified counternarrative of the transformation of East London was articulated from below. In events and with methods such as these an assemblage of voices and concerns entered the public realm in defiance of the Olympic consensus.10 As the zine publication distributed that day read:

24h Olympic State... brings together heterogeneous elements, acknowledging their differences and recognising their proximity. Like an archipelago, the collection of works we have summoned are islands separated by that which unites them. Against the Olympic fantasy of a dissent-less city, these projects investigate its discontents. They make visible what has been rendered obscure and obliterated; they listen to those who haven't been heard; they disturb the smooth image that is being fabricated.

\section{Part 2}

Soon after the Games were over, the International Olympic Committee collected their revenue and left. The Olympic Delivery Authority (ODA) and the London Organising Committee of the Olympic and Paralympic Games (LOCOG) were disbanded. Gone were also the Met officers on routine foot patrols, and the Army units that had guarded the Olympic fence. The huge advertising vinyls that covered Stratford's tower blocks were removed, and so were the Coca-Cola panels that prevented those crossing the Westfield shopping mall bridge from seeing the surrounding area. Most of the pop-up venues that had overoptimistically opened in Hackney Wick and Fish Island, catering to inexistent hordes of adventurous tourists, closed and left. Inside the Olympic Park, many temporary structures and venues were disassembled. Old horizons, buildings and neighbours came back into view - and with them, the scars left by the Olympic behemoth. The colossal task of "stitching the fringe", as the legacy plan announced, became painfully apparent. The development of the Olympic site had been based on isolating it from its environs - namely for security reasons - and reversing that would 
take more than a few bridges. A new public body responsible for re-articulating the relationship between the Queen Elisabeth Olympic Park and its surroundings, the London Legacy Development Corporation (LLDC), was introduced.

With the Olympics and its satellite organisations gone, lost was also the focal point of antagonism in the area for the best part of seven years. In Hackney Wick in particular, a new set of concerns became prominent, mostly related to the uncertain survival of the ecology of affordability that had defined the area in a context of increased development pressure. This was accompanied by a shift towards a more congenial relationship between local residents/practitioners and local authorities. (The development of a new local plan and the introduction of an arts and culture programme by the LLDC are two examples of new forums for dialogue).

It is in this context that I want to situate and examine the work of public works, a small art and architecture collective (formed at the time of writing by Torange Khonsari and Andreas Lang, plus a network of collaborators). public works has engaged with Hackney Wick through a number of projects since 2008, interrogating the area's history and intervening in its public realm. Their work can be easily described as "relational" according to the definition provided above. Here, too, social relations are both the raw material and the goal of the artistic process. Unlike most relational art, however, the relations and connections public works fosters exist outside the art world, and are in fact meant to be functional, i.e. to outlive the temporality of the project and be capable of intervening in their context. An example will make this clearer.

R-Urban Wick is the London leg of R-Urban, a European project initiated in France by L'atelier d'architecture autogérée (aaa) and defined as a participatory strategy for the development of "practices and networks of local resilience." The project brings together concerns with sustainability in a wide sense (ecological, economic, cultural, etc.) with the development of bottom-up strategies of "commoning" (more on this below). The overall aim is to explore citizen-led alternatives to dominant models of living, producing and consuming in cities, suburbs and rural areas. This is done through "initiating collaborative practices and creating solidarity networks, closing cycles between production and consumption, operating changes in lifestyles [and] acting ecologically at the level of everyday life”.11 In Hackney Wick, R-Urban is structured 
around four strands: the Wick on Wheels (aka WoW), a mobile recycling facility and workspace based on a repurposed milk float; Experiments in Household Knowledge, a series of collaborations exploring existing local ecological practice; the Wick Curiosity Shop, an archive for the dissemination of local history; and the Wick Sessions, talks and walks supporting an active knowledge exchange.12 The main focus of the project has been on re-use, that is, repurposing items and materials towards new uses (this is different from recycling, which consists in reprocessing items into new raw material "more 'up-cycling' for perpetual value than limited and finite 'down-cycling'”).13 Since the project started in 2012, more than 20 events and several publications have been produced. In them, the virtues and re-use possibilities of comfrey, burnt timber and old bathtubs (among other "minor" materials) have been demonstrated by ingenious practitioners [Fig. 4]. A rich culture of makeshift practices has been brought into public view.

The four strands favour distinct "modes of engagement" (making, dialoguing, experimenting, and making public), but have in common a methodological approach based on identifying relevant (and mostly unsanctioned) local knowledges and practices, and supporting them with access to a wider audience and connections with other practitioners and relevant actors (and ideally funding). R-Urban Wick aims to become an extension of these local dynamics - or more precisely, to provide an infrastructure that allows these makeshift practices to develop in their own terms and be recognised as valuable strategies. I will provide two examples to illustrate this point.

Frontside Gardens is a skatepark located on 67 Rothbury Road, on what used to be the site of Bangla TV. The site is owned by the LLDC, which designated it as an Interim Use Pilot Project in 2012, with a view to inform the strategy for the development of other interim use sites within the Olympic Park. Andrew Willis won the competition with a skatepark proposal, originally meant to last for just four months in the Summer of 2012, but still functioning as of November 2014 after several lease extensions. Willis self-built the skatepark with very little time and money, and using almost exclusively repurposed materials.

The appeal of the skatepark for R-Urban Wick was obvious: it was an actually existing experiment in reuse which relied on Willis' know-how and network of contacts, 
and involving complex negotiations with the local authorities and regulations (opening hours, insurance, health and safety, access to electricity, etc.). public works first supported the skatepark at the building stage, with open building workshops (during one of which the skatepark's service gate was built) [Fig. 5]. At a later stage, they mapped the skatepark's socio-material geography, tracing the origin of the different parts, making visible the complex relational network involved in sourcing the materials, and explaining the vernacular techniques of construction (and gardening) deployed. This research made clear that the "activation" of this type of new use cycles doesn't only involve materials, but crucially requires immaterial networks of skills and information. "Being in the know" regarding the availability of such materials, borrowing tools and techniques, and learning with/from others are all essential aspects of a project such as Frontside Gardens. public works' contribution was simple yet crucial: translating Willis' ingenuity and guerrilla tactics into a public resource and a method. A version of this mapping exercise was then published in the local newspaper, The Wick, in an attempt to distribute this knowledge more widely [Fig. 6]. Furthermore, this had a strategic importance in the local context: it highlighted the viability of a self-built and selfmanaged space, and turned its makeshift quality - typical of the area - into a plausible inspiration for the LLDC's temporary use strategy. More recently, Frontside Gardens has been one of the case studies included in a research project investigating the overlapping systems of values mobilised by temporary use interventions, a collaboration between public works and Queen Mary, University of London.14 In effect, R-Urban Wick tries to establish lines of communication between the rich landscape of vernacular practices of re-use it has identified and supported, and local policy decisions.

A second example is public works' strategic deployment of hosting as a technology of encounter, dialogue, and mutual learning. Experiments in Household Knowledge and the Wick Sessions both rely on hosting events (often in collaboration with other people) in which knowledge is shared and discussed. For example, a series of workshops and talks have been organised around the issue of sustainable energy production and waste management, all contributing towards the goal of building and setting up one or more micro anaerobic digesters in the area. In the UK this technology (based in the natural breakdown of organic materials into biogas) is most frequently developed on an 
industrial scale, but R-Urban Wick takes inspiration from their household use in India and China. At these events, innovators, entrepreneurs, neighbours and, crucially, those responsible for sustainability within the local authority, have participated and contributed with their different expertise. Rokiah Yaman, for example, took them to see the Camley Street Natural Park micro anaerobic digester, and discussed her prototype network of waste managers and biogas producers in Camden. At the time of writing, a workshop with a local school has been organised as part of Space Studios' People's Power art and technology programme, in which mini prototypes will be built as a way to engage students in the issue of DIY energy production. public works' mid-term plan is to install a fully functioning prototype at the premises of a R-Urban favourite: Thomas Fletcher's Rejuce - a fruit and veg juice drink made out of food waste gleaned daily from New Spitalfields Market (Fig. 7).

R-Urban Wick's long term goal is to establish a user-led public re-use centre in the Wick, translating the area's vernacular cultures of re-use into local policy. This aim relates to public works' relational approach to place-making, in which the production of public space relies on the co-production of the commons, that is, enacting spaces which are neither under state nor capitalist control, which are de-commodified, collective, shared, removed from the logic of market exchange. Co-producing urban commons also means altering the established hierarchies of propriety, responsibility and participation in urban matters, allowing non-experts to become full-fletched actors. As Fran Tonkiss has argued, these "minor" practices of commoning, often mundane in their methods (discussing, sharing, making, etc), should indeed be seen as acts of tactical urban design whose language is based on appropriations, informality, re-tooling, occupations, redistributions. These strategies for re-making the urban stand against the dominant forms of urbanisation based on the commodification and privatisation of space, and "form an infrastructure of common life that provides sites of autonomy, creativity and collectivity in the making and re-making of cities and subjects."15

In their practice, public works has shown an exquisite respect for practices that don't fit in the mainstream, and shown their commitment to take them seriously as models for rethinking the ways in which we inhabit our neighbourhoods. R-Urban 
Wick has indeed facilitated the production of spatial and knowledge commons, and in doing so contributed towards the project of a city collectively made from below [Fig. 6].

\section{Conclusion}

I have presented two distinct moments in the relationship between the Olympic site and Hackney Wick, as mediated by so many artistic projects. In the lead up to the Games, art, I argued, was effective in producing spaces of dissent which critically interrogated the effects of Olympic-led regeneration. The dominant consensus (the regulation of what could be said, seen and thought) was challenged through the articulation of new narratives, images and precepts which in turn produced new enunciating subjects and collectivities. In the case of Jim Woodall's 24-b Olympic State, the critique of surveillance was combined with the activation of the minor histories of the Lower Lea Valley.

The post-Olympic period appears characterised by a different sensibility, which responds to a new set of circumstances, marked by the redefinition of the relationship between the Olympic Park and its surrounding areas. In this context, public works' RUrban Wick has shown how artistic methods can contribute to the task of identifying and making public a local culture of the makeshift which may inform the future urbanisation of the area. Whereas in the first moment discussed the specificity of the artistic aesthetic experience provided the vehicle for the production and distribution of dissent, R-Urban Wick relies, on the contrary, on a relational practice that practically abandons the language of art (although not the funding that comes with it) in benefit of an unassuming everyday diction. The absence of the "art" signifier worked well towards the goal of generating actually working relationships, and the project has indeed proven its capacity to foster relations of affinity and cross-fertilisation between a wide range of local actors, including local business and authorities.

\section{Captions}

Fig. 1: Olympic State. Gallery installation, interior view. Photo by the author.

Fig. 2: Poster/flyer for 24-h Olympic State. Designed by Jim Woodall.

Fig. 3: 24-h Olympic State. Photo by the author. 
Fig. 4: Build a carbonised plant regulated growing system workshop, part of Experiments in Household Knowledge. Photo by public works.

Fig. 5: public works workshop at Frontside Gardens. Photo by public works.

Fig. 6: Socio-material map of re-use at Frontside Gardens. Designed by public works, Sam Brown and Darren Ellis. Originally published in The Wick, no. 3.

Fig. 7: Andreas Lang of public works leading a tour of the makeshift spaces of Hackney Wick. Frontside Gardens is the enclosed space in the background, on the centre-right of the image. Photo by the author. Fig. 8: Diagram of a micro anaerobic digester by public works. Taken from public works' Beyond Received Wisdom: An Anthology of Experiments in Household Knowledge (London, 2013).

Notes

(1) For a compilation of this work, see Powell, Hilary, and Isaac Marrero-Guillamón, eds., The Art of Dissent: Adventures in London's Olympic State (London: Marshgate Press, 2012).

(2) Learning from Barcelona: Art, Real Estate and the pre-Olympic city, Birkbeck Stratford, 28-29 January 2011. The conference marked the beginning of a two-year research project led by Mari Paz Balibrea and funded by the Spanish Ministry of Education: Looking at/for the Militant City: political space and audiovisual art in two Olympic cities - Barcelona and London. I conducted the post-doctoral research that informs this article as part of this project.

(3) muf art/architecture, Creative Potential: Hackney Wick and Fish Island (London, 2009).

(4) See Sloterdijk, Peter, 'Atmospheric Politics', in Making Things Public, ed. by Bruno Latour and Peter Weibel (Cambridge, MA: MIT Press / ZKM Karlsruhe, 2005), pp. 944-51.

(5) See Ford, Laura Oldfield, Savage Messiah (London; New York: Verso, 2011).

(6) Bourriaud, Nicolas, Relational Aesthetics (Dijon: Les Presse Du Reel, 1998), pp. 113.

(7) Bishop, Claire, 'Antagonism and Relational Aesthetics', October, 110 (2004), 51-79.

(8) Rancière, Jacques, 'Aesthetic Separation, Aesthetic Community: Scenes from the Aesthetic Regime of Art', Art E Research, 2 (2008), 1-15

(9) Ibid., p. 5.

(10) Of course, artists and cultural practitioners played another, much more central role in relation to the Olympics during the same period. It would be rather naïve to praise the spaces of dissent described here without acknowledging that the hegemonic role of art and culture in relation to the Games was one of expedient collaboration. The Cultural Olympiad, for instance, spanned over four years, had a budget of $£ 126.6$ million and involved more than 40,000 artists and 177,000 activities (Reflections on the Cultural Olympiad and the London 2012 Festival, London: Arts Council England, 2013). The Art in the Park programme, a series of public art commissions in the Olympic Park, had a budget of $£ 11$ million for 25 permanent and 11 temporary projects (Olympic Delivery Authority, 'Minutes of 62nd Board Meeting', 29 March 2012). It is therefore necessary to take into consideration the sheer scale of the official arts and culture programming when situating the work and impact of the projects described above.

(11) aaa, 'R-URBAN - participative strategy for development, practices and networks of local resilience', <http://www.urbantactics.org/projects/rurban/rurban.html > [accessed 3/11/14].

(12) The last two predated R-Urban and were integrated under its umbrella.

(13) Brown, Sam, 'Re-use in Hackney Wick', The Wick, 3 (2013): 11.

(14) "Re-valuing Temporary Urban Use", funded by the AHRC-Creative Works London and led by David Pinder and Mara Ferreri.

(15) Tonkiss, Fran, Cities by Design: The Social Life of Urban Form (Cambridge and Malden: Polity Press, 2013), pp.176. 
The art of assembling/relation

Spaces of relation:

Relational space:

The production of relational space

The view from HW

Working with relations

Relational art, dissent, and collaboration

The politics of relations

Relations, dissent, collaboration: the view from Hackney Wick 